\title{
The 5S ribosomal RNA gene clusters in Tetrahymena thermophila: strain differences, chromosomal localization, and loss during micronuclear ageing
}

\author{
Sally Lyman Allen, Paul R. Ervin, Ning C. McLaren, and Randall E. Brand \\ Division of Biological Sciences, The University of Michigan, Ann Arbor, MI 48109, USA
}

Summary. The organization of the $5 \mathrm{~S}$ genes in the genome of Tetrahymena thermophila was examined in various strains, with germinal ageing, and the $5 \mathrm{~S}$ gene clusters were mapped to the MIC chromosomes. When MIC or MAC DNA is cut with the restriction enzyme EcoRI, electrophoresed, blotted, and probed with a $5 \mathrm{~S}$ rDNA probe, the banding patterns represent the clusters of the $5 \mathrm{~S}$ rRNA genes as well as flanking regions. The use of long gels and $60 \mathrm{~h}$ of electrophoresis at $10 \mathrm{~mA}$ permitted resolution of some 30-35 5S gene clusters on fragments ranging in size from $30-2 \mathrm{~kb}$ (bottom of gel). The majority of the $5 \mathrm{~S}$ gene clusters were found in both MIC and MAC genomes, a few being MIC limited and a few MAC limited. The relative copy number of $5 \mathrm{~S}$ genes in each cluster was determined by integrating densitometric tracings made from autoradiograms. The total number of copies in the MAC was found to be $33 \%$ greater than in the MIC. When different inbred strains were examined, the majority of the $5 \mathrm{~S}$ gene clusters were found to be conserved, with a few strain-specific clusters observed. Nine nullisomic strains missing both copies of one or more MIC chromosomes were used to map the 5S gene clusters. The clusters were distributed non-randomly to four of the five MIC chromosomes, with 17 of them localized to chromosome 1 . A deletion map of chromosome 1 was constructed using various deletion strains. Some of these deletion strains included B strain clones which had been in continuous culture for 15 years. Losses of $5 \mathrm{~S}$ gene clusters in these ageing MIC could be attributed to deletions of particular chromosomes. The chromosomal distribution of the $5 \mathrm{~S}$ gene clusters in Tetrahymena is unlike that found for the well-studied eukaryotes, Drosophila and Xenopus.

\section{Introduction}

Both a germinal and somatic nucleus coexist within the cytoplasm of the ciliated protozoan Tetrahymena thermophila. The germinal nucleus (MICronucleus) is dormant, diploid, and is the developmental source of the transcriptionally-active, DNA-rich, somatic nucleus (MACronucleus). During development of the MAC the DNA content is replicated to a value 23-32 times that of the MIC, the chromosomes fragment, interstitial deletions occur, and some sequences are underreplicated or eliminated, some are

offprint requests to: S.L. Allen overreplicated, and others are rearranged (Yao et al. 1979; Yao and Yao 1981; Yao 1982; Yao et al. 1984; Brunk et al. 1982; Iwamura et al. 1982; Callahan et al. 1984). Accompanying the genomic changes are alterations in the chromatin composition and the acquisition of the ability to transcribe (Gorovsky 1980).

Most of the sequences studied in Tetrahymena belong to the repeated gene category: the 17-26 S ribosomal RNA genes, the $5 \mathrm{~S}$ ribosomal RNA genes, and others of unknown function. A single copy of the 17-26 S rRNA gene is integrated at the $r d n A$ locus on chromosome $2 \mathrm{~L}$ in the $\mathrm{MIC}$ (Bruns 1982; Yao and Gall 1977). During MAC development the gene is excised and amplified to form 10-15,000 extrachromosomal palindromic molecules. In the mature MAC there are 200-300 copies of these extrachromosomal palindromes, or 400-600 copies of the 17-26 S rRNA gene, per haploid genome (Yao et al. 1974; Pearlman et al. 1979). In contrast, normal replication occurs for the $5 \mathrm{~S}$ rRNA genes, since there are 300-350 copies of these genes per haploid genome in both MIC and MAC (Kimmel and Gorovsky 1976). The $5 \mathrm{~S}$ genes appear to be tandemly repeated in head to tail linkages, organized into about 15-20 clusters of tandem repeats per haploid genome in both nuclei (Kimmel and Gorovsky 1978). Each repeating unit appears to be approximately 280 base pairs in length, consisting of a 120 base pair gene and a 160 base pair AT-rich spacer region (Kimmel and Gorovsky 1978). The restriction enzyme EcoRI does not cleave within these repeats. When DNA is cut with EcoRI, electrophoresed, blotted, and probed with a $5 \mathrm{~S}$ rDNA probe, the banding patterns represent the clusters of the 5S rRNA genes as well as some of the flanking regions. A modest difference in the banding patterns was observed between MIC and MAC DNA, suggesting rearrangement (Kimmel and Gorovsky 1978).

The 5S rRNA genes occur in tandemly repeated clusters in all eukaryotic organisms (Long and Dawid 1980). In prokaryotes and two lower eukaryotes, the yeast Saccharomyces cerevisiae and the cellular slime mold Dictyostelium discoideum, the 5S genes are linked to the larger species of rRNA genes (Pace 1973; Rubin and Sulston 1973; Maizels 1976). However, the $5 \mathrm{~S}$ genes are not linked to the 18-28 S rRNA genes in the acellular slime mold, Physarum polycephalum, as is the case for higher eukaryotic organisms (Hall and Braun 1977). The latter situation also appears to apply to Tetrahymena (Kimmel and Gorovsky 1978).

Two very different chromosomal distributions are observed for the $5 \mathrm{~S}$ genes: either they are clustered at a single 
site or dispersed at multiple sites (Long and Dawid 1980). In Drosophila melanogaster there is a single cluster of about $1605 \mathrm{~S}$ genes on the second chromosome. In Xenopus the $5 \mathrm{~S}$ genes are distributed to the telomere of the long arm of many, if not all, chromosomes; moreover, there are two familes of $5 \mathrm{~S}$ genes, a large oocyte-specific family numbering in the thousands, and a smaller somatic family numbering in the hundreds, the structural details of the genes varying in different species. With the advent of nullisomic strains of $T$. thermophila it is possible now to map the $5 \mathrm{~S}$ gene clusters in the MIC by molecular methods to one or more of the five chromosomes, and to discover which pattern of chromosomal organization of the clusters applies to Tetrahymena. This paper will describe our observations on the stability of the 5S rRNA gene clusters in the MIC of various strains, and with germinal ageing, and the mapping of the clusters to the chromosomes.

\section{Materials and methods}

\section{Strains}

All cell lines were clones derived from inbred strains or their hybrids:

Inbred strains. A-17686, B-2079X2, C3-3685, D-25772a (ATCC 30845), D/1( $\left.\mathrm{I}_{1}\right)-5771$ (ATCC 30847), DI(DxD/1).

B strain. B-2079X2, B-2079X6, B-18684b, B-18684, B$18687 \mathrm{~N}, \mathrm{~B}-18687 \mathrm{~B}$.

Nullisomic strains. CU354 (nulli-5), CU358 (nulli-3,4,5), CU359 (nulli-2,3,5), CU362 (nulli-3), CU371 (nulli-1R, 2R) CU372 (nulli-1R, 3), CU373 (nulli-1R), CU383 (nulli-4), CU404 (nulli-2,3).

The relationship of the inbred strains is diagrammed in Fig. 1. Strains A, B, C, and D were derived from crosses of wild isolates, or crosses of wild isolates to $B$ strain clones, and then inbred by selfing for 16-25 generations. Strains $\mathrm{C} 2$ and $\mathrm{C} 3$ were generated by genomic exclusion from the same AC hybrid crossed to C* (Allen 1967a). Strain D/1 (or $\mathrm{I}_{1}$ ) is a congenic strain of strain $\mathrm{D}$, obtained by outcrossing $\mathrm{D}$ to $\mathrm{C} 2$, with selection of certain $\mathrm{C} 2$ genes during 12 successive backcrosses to $\mathrm{D}$, followed by genomic exclusion (Allen and Lee 1971). In 1968 when it was clear that the cells could be reliably frozen, further inbreeding was discontinued for most of the strains. Samples of some of the D and $\mathrm{D} / 1$ clones were sent to the American Type Culture Collection in 1977 where they were frozen and given ATCC numbers.

The B-1868 clones orginated from cross A68-316, carried out at the University of Michigan. B-18684 and 7 are sister clones from the same inbred mating pair, $4 \mathrm{~b}$ from a different pair. Two different samples of clone B-18687 were available from different laboratories: B-18687B from P.J. Bruns (Cornell University) and B-18687N from D.L. Nanney (University of Illinois). Two clones from different pairs (B-18686 and 7) were crossed by L. Jenkins (University of Iowa) to give a nineteenth generation. B-19755 was put through genomic exclusion by a cross to $\mathrm{A} *$ to produce the B-2079 clones. B-2079X2 and X6 are sister clones from the same round 2 pair and were obtained from L. Jenkins.

The nullisomic strains have a B strain background and

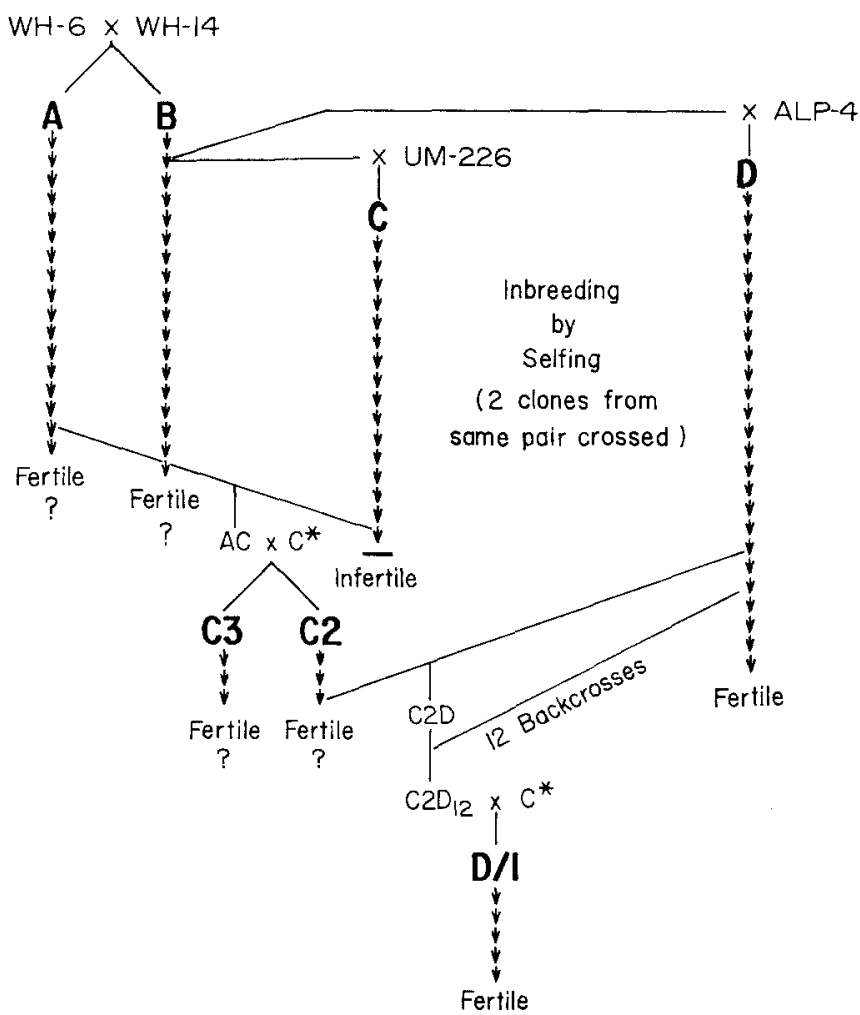

Fig. 1. Origin of inbred strains of Tetrahymena thermophila. Each small vertical arrow represents one generation of inbreeding

were obtained from P.J. Bruns who developed them. Their genesis has been described in some detail recently by Bruns et al. (1983).

\section{Growth of cultures}

For nuclear preparations, test-tube cultures were grown in $1 \%$ proteose-peptone for 2 days at $30^{\circ} \mathrm{C}$. Flasks containing PP210 medium ( $2 \%$ proteose-peptone, $10 \mu \mathrm{MFeCl}_{3}$ ) were inoculated with test-tube cultures, grown for $24 \mathrm{~h}$ in a shaker water bath at $30^{\circ} \mathrm{C}$, and the cell concentration determined. Five $\mathrm{L}$ diphtheria toxin bottles containing $3 \mathrm{~L}$ of PP210, $3 \mathrm{ml}$ of antifoam B (Baker) and penicillin-streptomycin $(250 \mu \mathrm{g} / \mathrm{ml})$ were inoculated with an aliquot of cells sufficient to give a final concentration of $2-3 \times 10^{5}$ cells $/ \mathrm{ml}$ after growth at $30^{\circ} \mathrm{C}$ with gentle aeration in a large water bath. Since the nullisomic strains appeared to be contaminated to various degrees with an unknown fungus, a fungicide was added to the cultures. We used two fungicides: fungizone $(0.25 \mathrm{mcg} / \mathrm{ml})$ found in Antibiotic-Antimycotic (Gibco Laboratories) or mycostatin (5 units/ml; Squibb Nystatin). Without fungicide, the nuclei would not sediment during centrifugation.

\section{Nuclear isolation and $D N A$ preparation}

Nuclei were isolated using the Percoll gradient method (Allen et al. 1983). MAC and MIC DNA was isolated by $\mathrm{CsCl}$ gradient centrifugation, following the procedure outlined in Allen et al. (1983). MIC DNA was used only if it contained less than $1 \mathrm{MAC}$ in $1500 \mathrm{MIC}$. This level of purity insured that any slight contamination by MAC would be less than what our system could detect. The purification of MIC involved collecting, concentrating, and homogeniz- 
ing the cells, differential centrifugation, and repeated Percoll gradient centrifugation until the nuclei reached the desired purity.

\section{Hybridization probe}

Plasmid pDP5, obtained from D. Pederson (University of Rochester), contains a $280 \mathrm{bp}$ BamHI fragment of a MIC 5S rRNA gene plus AT-rich spacer cloned into the BamHI site of pBR322 (Pederson, personal communication). DNA from this plasmid was used to transform $E$. coli strain HB101. Plasmid DNA was isolated by a modification of the SDS/high salt cleared lysate procedure (Gunsalus et al. 1979) followed by $\mathrm{CsCl} /$ ethidium bromide gradient centrifugation in a vertical rotor, and the DNA was labeled in vitro wtih $\alpha^{32} \mathrm{P}$ to $1 \times 10^{8} \mathrm{cpm} / \mu \mathrm{g}$ by a modified nick translation procedure (Maniatis et al. 1975; Rigby et al. 1977).

Restriction endonuclease digestion, gel electrophoresis, and Southern blots

Nuclear DNA was digested with the restriction enzyme, EcoRI, using the conditions described by the supplier of the enzyme, Bethesda Research Laboratories. Five $\mu \mathrm{g}$ of DNA were digested per reaction mixture in a total volume of $20 \mu \mathrm{l}$. Two units of enzyme were used per $\mu \mathrm{g}$ of DNA and digestion was carried overnight to ensure complete digestion. The DNA was heat shocked to deactivate the enzyme and prevent reannealing of the ends before loading into wells in agarose gels. To visually monitor electrophoresis bromphenyl blue dye was added to the reaction mixture just before electrophoresis. The gels used were $0.6 \%$ agarose in Tris-borate buffer containing ethidium bromide, poured into plates for a 12 inch long, 6 inch wide submarine gel. The maximum capacity of the well was $50 \mu 1$. The DNA was electrophoresed for $60 \mathrm{~h}$ at $10 \mathrm{~mA}$ or until the HindIII digested lambda marker, which contains a $1.96 \mathrm{~kb}$ fragment, was one inch from the end of the gel.

After electrophoresis the gels were irradiated for $10 \mathrm{~min}$ with a broad spectrum UV lamp. During this time the DNA was visualized and the distances traversed by the marker fragments measured. The gels were then prepared for transfer of the DNA to nitrocellulose filters (Schleicher and Schuell) using the method of Southern (1975) with modifications. During DNA transfer each gel was kept on the plate used for electrophoresis to prevent distortion due to its low agarose concentration. During preparation for transfer, the length of the time of each wash was extended in proportion to the size of the gel.

\section{Hybridization and autoradiography}

After the filters were baked for $1.5 \mathrm{~h}$ at $80^{\circ} \mathrm{C}$, they were loaded into sealable plastic bags (Hamilton Beach), soaked for $0.5 \mathrm{~h}$ at $62^{\circ} \mathrm{C}$ in $3 \times \mathrm{SSC}$ (SSC $=0.15 \mathrm{M}$ sodium chloride, $0.015 \mathrm{M}$ sodium citrate, $\mathrm{pH} 7.0$ ), and prehybridized for $3-5 \mathrm{~h}$ at $62^{\circ} \mathrm{C}$ in $10 \times$ Denhardt's solution (Denhardt 1966), $3 \times \mathrm{SSC}, 0.1 \% \mathrm{SDS}$, and $25 \mu \mathrm{g} / \mathrm{ml}$ of denatured carrier (calf thymus) DNA. Filters were hybridized for $36 \mathrm{~h}$ at $62^{\circ} \mathrm{C}$ immediately following prehybridization. The hybridization solution contained fresh prehybridization mixture with the addition of the nick translated probe $\left(6 \times 10^{7} \mathrm{cpm}\right)$.

The hybridized filters were washed four times in $2 \times \mathrm{SSC}$ containing $1 \% \mathrm{SDS}$ for $30 \mathrm{~min}$ at $65^{\circ} \mathrm{C}$. They were then washed once in $0.2 \times \mathrm{SSC}$ containing $1 \% \mathrm{SDS}$ for $30 \mathrm{~min}$, then once in $2 \times \mathrm{SSC}$ for $10 \mathrm{~min}$, both at $65^{\circ} \mathrm{C}$. The filters were dried for $2 \mathrm{~h}$ and exposed to Kodak XAR-5 film at $-80^{\circ} \mathrm{C}$ with an intensifying screen for 1-10 days depending on the radioactivity of the filter following the washes. Several exposures were made for each filter to obtain optimum band crispness.

\section{Densitometry}

Densitometric tracings were made of the $5 \mathrm{~S}$ rRNA gene pattern from autoradiograms of the $E c o$ RI digested nuclear DNA's. These tracings were made using a Joyce-Loebl densitometer (Model Mk.111C). The curve was integrated using a Numonics digitizer computer interfaced with a Hewlett-Packard computer (Model 9825A) and a program graciously provided by L.I. Grossman (University of Michigan). Using the integrations we were able to determine the areas under the peaks and to relate them to relative copy number of the $5 \mathrm{~S}$ genes for each cluster.

\section{Results}

The majority of the $5 S r R N A$ gene clusters are found in both MIC and MAC genomes, a few being MIC limited and a few $M A C$ limited

The use of long gels and $60 \mathrm{~h}$ of electrophoresis at $10 \mathrm{~mA}$ permitted increased resolution of the $5 \mathrm{~S}$ gene clusters. Instead of 15-20 clusters, we could easily observe $30-355 \mathrm{~S}$ gene clusters ranging in size from 30 to $2 \mathrm{~kb}$ (bottom of gel) (Fig. 2). The number of fragments bearing clusters, and their total $\mathrm{kb}$, was similar in the MIC and MAC genomes if the two largest MAC fragments $(30$ and $28 \mathrm{~kb})$ are ignored. The inclusion of these large fragments would bring the number of clusters to 34 in the MAC compared to 32 for the MIC in the DI strain. The total $\mathrm{kb}$ of the fragments bearing $5 \mathrm{~S}$ gene clusters along with their flanking sequences is $261-319 \mathrm{~kb}$ for the MAC, depending upon the inclusion of the 30 and $28 \mathrm{~kb}$ fragments for the MAC, compared to $263 \mathrm{~kb}$ for the MIC.

Since the $5 \mathrm{~S}$ repeat (gene and spacer) is $280 \mathrm{bp}$ in length, with a total length of $260 \mathrm{~kb}$ for 32 fragments, there should be enough room for 928 repeats. On the basis of saturation hybridization kinetics Kimmel and Gorovsky (1976) concluded that there were 295 and 350 5S genes per haploid MIC and MAC genomes, respectively. With 32-34 fragments bearing clusters of $5 \mathrm{~S}$ genes, we would expect an average size cluster to contain about ten $5 \mathrm{~S}$ repeats. The average size fragment bearing a cluster of ten $5 \mathrm{~S}$ repeats would be expected to have a length of $8.1-9.4 \mathrm{~kb}$ (excluding fragments smaller than $2 \mathrm{~kb}$ ) leaving room for some $5.3-6.6 \mathrm{~kb}$ of flanking sequences. We attempted to quantitate the relative number of $5 \mathrm{~S}$ repeats in each cluster by making densitometric tracings of several autoradiograms similar to that shown in Fig. 2 and measuring the area under each peak using a digitizer computer. These absolute values were then compared. In many cases the values grouped around points that were integers of some minimal value. For each tracing a minimal value was chosen which, when multiplied by a series of integers, gave the best fit to the grouped values. A relative intensity could be assigned to a $5 \mathrm{~S}$ gene cluster based on the area under its peak compared to the minimal value for each tracing. Several integrations were performed on tracings of different autoradio- 


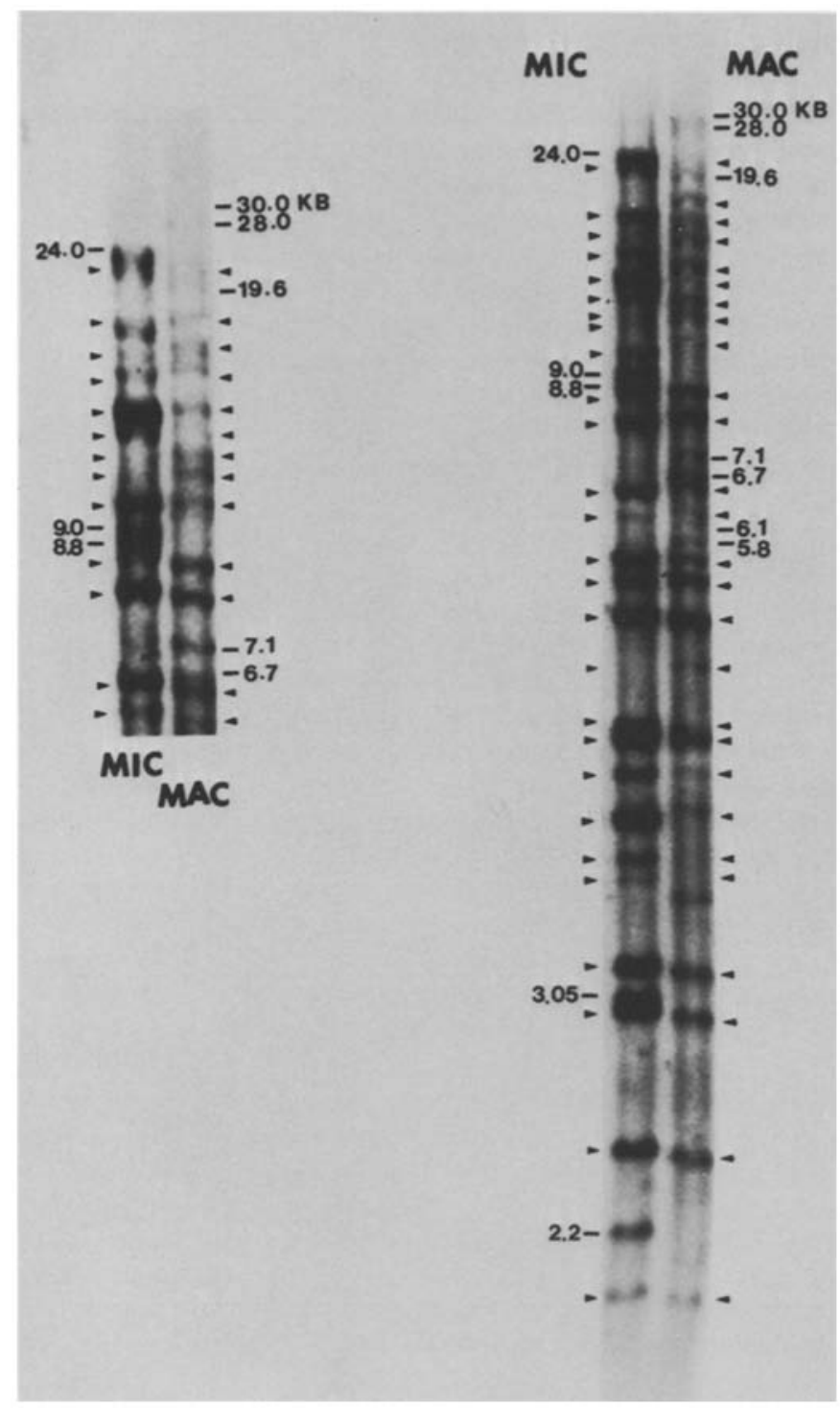

Fig. 2. Autoradiogram of Southern blot of DNA from micronucleus (MIC) or macronucleus (MAC) probed with $\alpha^{32} \mathrm{P}$-labeled pDP5 (which contains one copy of the 5S DNA and spacer). Each DNA was digested with EcoRI $(5 \mu \mathrm{g} /$ lane), electrophoresed in an $0.6 \%$ agarose submarine gel, 12 inches long, for $60 \mathrm{~h}$ at $10 \mathrm{~mA}$, and blotted to nitrocellulose. Arrowheads point to fragments common to MIC and MAC. Fragments that are MIC limited or MAC limited are indicated by their size in kilobases $(\mathrm{kb})$

grams, and the relative intensities were averaged for each $5 \mathrm{~S}$ gene cluster. The results of this analysis are given in terms of relative copy numbers for the clusters in MIC and MAC DNA in Table 1. The minimum total number of copies of 5S genes is 148 for the MIC and 206 for the MAC. The average cluster contains $5-6$ repeats, the largest clusters about 10-11 repeats. These figures could be doubled if the fragment assumed to have two copies of the $5 \mathrm{~S}$ genes actually has four copies.

Twenty-seven fragments bearing $5 \mathrm{~S}$ gene clusters are found in both MIC and MAC of the DI strain (demarked by small arrows in Fig. 2). Five of the clusters $(2.2,3.05$, $8.8,9.0$, and $24.0 \mathrm{~kb}$ ) are limited to the MIC and seven clusters $(5.8,6.1,6.7,7.1,19.6,28.0$, and $30.0 \mathrm{~kb})$ are limited to the MAC. Thus, the majority of the $5 \mathrm{~S}$ gene clusters
Table 1. Relative intensities (relative copy numbers of $5 \mathrm{~S}$ genes) of the clusters in MIC and MAC DNA

\begin{tabular}{|c|c|c|c|}
\hline $\begin{array}{l}\text { Fragment } \\
\text { no. }\end{array}$ & $\begin{array}{l}\text { Size } \\
\mathrm{kb}\end{array}$ & $\mathrm{MIC}^{\mathrm{a}}$ & $\mathrm{MAC}^{\mathrm{a}}$ \\
\hline 1 & 30.0 & - & 4 \\
\hline 2 & 28.0 & - & 5 \\
\hline 3 & 24.0 & \multirow{2}{*}{$>11$} & - \\
\hline 4 & 21.8 & & 4 \\
\hline 5 & 19.6 & - & 5 \\
\hline 6 & 18.0 & 6 & 6 \\
\hline 7 & 17.2 & 3 & 5 \\
\hline 8 & 16.0 & 7 & 6 \\
\hline 10 & 14.3 & 9 & 7 \\
\hline 11 & 12.5 & 5 & 6 \\
\hline 12 & 11.5 & \multirow[t]{2}{*}{$>4^{\mathrm{c}}$} & 4 \\
\hline 13 & 10.5 & & 4 \\
\hline 15 & 9.5 & 4 & 3 \\
\hline 16 & 9.0 & 3 & - \\
\hline 17 & 8.8 & 3 & - \\
\hline 18 & 8.1 & 3 & 6 \\
\hline 19 & 7.6 & 6 & 7 \\
\hline 20 & 7.1 & - & \\
\hline 21 & 6.9 & - & $>6$ \\
\hline 22 & 6.7 & - & 5 \\
\hline 23 & 6.6 & 5 & 6 \\
\hline 24 & 6.5 & 3 & 5 \\
\hline 25 & 6.1 & - & 5 \\
\hline 26 & 5.8 & - & 5 \\
\hline 27 & 5.7 & 6 & 6 \\
\hline 28 & 5.5 & 4 & 8 \\
\hline 30 & 5.1 & 7 & 11 \\
\hline 31 & 4.7 & $-?$ & $6^{\mathrm{b}}$ \\
\hline 34 & 4.35 & 5 & \multirow{2}{*}{$>10$} \\
\hline 35 & 4.3 & 6 & \\
\hline 36 & 4.1 & 4 & $4^{b}$ \\
\hline 38 & 3.9 & 8 & 8 \\
\hline 40 & 3.7 & 4 & $8^{c}$ \\
\hline 41 & 3.6 & $2^{\circ}$ & 8 \\
\hline 43 & 3.2 & 6 & 8 \\
\hline 44 & 3.05 & 4 & - \\
\hline 45 & 2.95 & 6 & 8 \\
\hline 47 & 2.45 & 6 & 10 \\
\hline 48 & 2.2 & 4 & - \\
\hline 49 & 2.0 & 4 & 7 \\
\hline \multicolumn{2}{|c|}{ Total number of copies } & 148 & 206 \\
\hline
\end{tabular}

\footnotetext{
a Average of 5 sets of data

b Only one value available

- Only two values available
}

are found on fragments of identical size in both MIC and MAC, as first observed by Kimmel and Gorovsky (1978). However, it is possible that differences between MIC and MAC may occur in the number of repeats in a cluster found on fragments of the same size. For 16 of the 27 fragments found in both MIC and MAC, the MAC cluster contained a slightly greater number of repeats than the corrresponding MIC cluster.

The majority of the 5S rRNA gene clusters are conserved in different strains, with a few strain-specific clusters observed

A striking feature of the data presented by autoradiography of the DNA from different strains is the lack of variability encountered in the number of fragments bearing clusters 
Table 2. 5S rRNA gene clusters in different strains

\begin{tabular}{lllll}
\multicolumn{2}{l}{ Source of DNA } & & \multicolumn{2}{l}{ No. of clusters } \\
\cline { 1 - 1 } Strain & Clone & & MIC & MAC $^{\mathrm{a}}$ \\
\hline A & A-17686 & 32 & 34 \\
B & B-2079X2 & 32 & 31 \\
C3 & C3-3685 & 32 & $32^{\mathrm{b}}$ \\
D & D-25772a & 32 & $34^{\mathrm{b}}$ \\
DI & Population & 32 & $34^{\mathrm{b}}$ \\
I & I $_{1}-5771$ & 31 & 33 \\
\hline
\end{tabular}

a The $30 \mathrm{~kb}$ and $28 \mathrm{~kb}$ clusters are found in the MAC of all strains, except for the B-2079 clones. These clones do not have the $30 \mathrm{~kb}$ cluster

$b$ There is clonal variation both within and between clones of these strains as to which MAC fragments are present, and their total number (Allen et al., manuscript submitted)

of $5 \mathrm{~S}$ genes in the MIC and MAC (Table 2). Some 32 clusters are observed in the MIC in these strains. A similar number of clusters is observed in the MAC, as found for the DI strain, although the largest cluster $(30 \mathrm{~kb})$ is absent from two B strain clones.

When the pattern of fragments is examined more closely, the level of variability between MIC genomes is low. Table 3 shows the distribution of the $5 \mathrm{~S}$ gene clusters in different strains: those that are MIC limited, those that are found in both the MIC and MAC, and those that are MAC limited. Twenty-five clusters (two MIC-limited and 23 in MIC and MAC) are identical in the MIC of all strains, six clusters occur in the MIC of all but one strain, and one cluster is present in the MIC of all but two strains. The fact that most MIC clusters are found in the MIC of all strains would seem to indicate that the 5S rRNA genes are conserved in their organization in the T. thermophila genome. Any differences seen in the various genomes might be due to genetic differences that reflect the origin of the strains (Fig. 1). For example, the $2.65 \mathrm{~kb}$ fragment that is visible in A strain MIC also appears in the MIC of strain $\mathrm{C} 3$ and in the MAC of both A and C3. This fragment also appears after several sexual generations in some clones of the DI strain. This gene sequence, or at least this spacing of $E c o$ RI sites surrounding the $5 \mathrm{~S}$ gene cluster, must be derived from the A strain since all the strains containing this fragment have some percentage of their genome derived from the $\mathrm{A}$ strain. There is also a MIC-limited fragment that is $8.8 \mathrm{~kb}$ in size which is present in B strain MIC. This fragment also shows up in the MIC of strains D, I, and DI, suggesting that it is a sequence derived from the $B$ strain which has persisted since the genesis of strain D from an outcross of ALP-4 to strain B. A few strain-specific clusters are also observed. Some clusters show specificity for one strain, such as the MIClimited $3.3 \mathrm{~kb}$ fragment found only in strain $\mathrm{C} 3$, or absence in a particular strain, such as the MIC-limited $3.05 \mathrm{~kb}$ fragment absent in strain C3.

The SS rRNA gene clusters are distributed to four of the five MIC chromosomes

Genes can be localized to specific MIC chromosomes using the nullisomic strains developed by P.J. Bruns (Bruns et al. 1983). The nullisomic strains have a B strain background

Table 3. Distribution of $5 \mathrm{~S}$ gene clusters in different strains

\begin{tabular}{lllll}
\hline MIC & & \multicolumn{2}{l}{ MAC } \\
\cline { 1 - 1 } $\begin{array}{l}\text { No. } \mathrm{kb} \\
\text { of } \\
\text { clus- } \\
\text { ters }\end{array}$ & & $\begin{array}{l}\text { No. kb } \\
\text { of } \\
\text { clus- } \\
\text { ters }\end{array}$ \\
\hline MIC limited & & \multicolumn{3}{l}{} \\
2 & 33.0 & $(24.0+9.0)$ & - & - \\
1 & 3.05 & (except C3) & - & - \\
1 & 2.2 & (except A) & - & - \\
1 & 3.3 & (C3 only) & - & - \\
1 & 8.8 & (B, D, DI, I only) & - & - \\
\hline
\end{tabular}

MIC and MAC

$23 \quad 181.05$

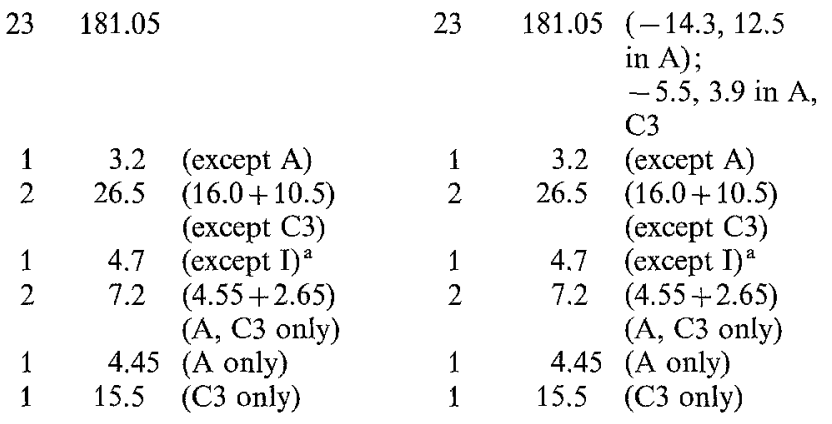

\begin{tabular}{llrrl}
\multicolumn{2}{l}{ MAC limited } & & & \\
- & - & 5 & 89.5 & (30, 28, 19.6, 6.1 \\
& & & & $5.8)$ \\
- & - & 1 & 6.7 & (except C3) \\
- & - & 1 & 7.1 & (A, B, I, DI) \\
- & - & 1 & 6.9 & (C3, D, DI?) \\
- & - & 1 & 5.3 & (A, C3 only) \\
- & - & 1 & 9.7 & (A only) \\
- & - & 1 & 7.8 & (B only) \\
\hline
\end{tabular}

a Missing both the 4.7 and 4.65 cluster

and are heterokaryons. They lack both copies of one or more of the five chromosomes of the MIC, but are viable since their MAC are intact and the MAC are the nuclei responsible for gene expression. When MIC DNA blots from normal and nullisomic strains are probed with a sequence, any bands missing from the hybridization spectrum of the nullisomic MIC DNA blot must be localized on the missing chromosome(s). Nullisomic strains lacking all but chromosome 1 have been generated, although some strains have deletions for part of chromosome 1 .

Nine nullisomic strains were used to map the $5 \mathrm{~S}$ gene clusters. Two of the strains were triple nullisomics, one was a double nullisomic, three were single nullisomics, and three contained deletions of different length for chromosome 1. The results are shown in Table 4. Of the 32 MIC 5S gene clusters, $2 \mathrm{~kb}$ or larger, present in the B strain, 29 could be mapped. Their chromosomal assignment is given. The clusters are distributed to four of the five chromosomes. None occur on chromosome 2. Seventeen clusters appear to be localized to chromosome 1 . Of the 17 clusters mapping to chromosome 1,11 map to the right arm of chromosome 1 (see Fig. 3). The three clusters that could not be mapped show a similar but odd behavior: they are absent in CU358 (nulli-3, 4, 5) but present in all the other null- 
Table 4. Mapping 5S gene clusters using MIC of nullisomic strains

\begin{tabular}{|c|c|c|c|c|c|c|c|c|c|c|c|c|}
\hline $\begin{array}{l}\text { Frag- } \\
\text { ment } \\
\text { no. }\end{array}$ & $\mathrm{kb}$ & $\begin{array}{l}\text { B-2079X2 } \\
\text { control }\end{array}$ & $\begin{array}{l}\text { CU358 } \\
-3,4,5\end{array}$ & $\begin{array}{l}359 \\
-2,3,5\end{array}$ & $\begin{array}{l}404 \\
-2,3\end{array}$ & $\begin{array}{l}362 \\
-3\end{array}$ & $\begin{array}{l}383 \\
-4\end{array}$ & $\begin{array}{l}354 \\
-5\end{array}$ & $\begin{array}{l}371 \\
-1 \mathrm{R}, 2 \mathrm{R}\end{array}$ & $\begin{array}{l}373 \\
-1 \mathrm{R}\end{array}$ & $\begin{array}{l}372 \\
-1 \mathrm{R}, 3\end{array}$ & $\begin{array}{l}\text { Chro- } \\
\text { mo- } \\
\text { some }\end{array}$ \\
\hline 4 & 21.8 & + & - & + & + & + & - & + & + & + & + & 4 \\
\hline 6 & 18.0 & + & + & + & + & + & + & + & - & - & + & $1 \mathrm{R}$ \\
\hline 7 & 17.2 & + & - & $-?$ & $-?$ & - & + & + & + & + & $+?$ & $3 ?$ \\
\hline 11 & 12.5 & + & + & $+?$ & + & + & + & + & + & + & + & $1 \mathrm{~L}$ \\
\hline 12 & 11.5 & $\mathrm{f}$ & + & $+?$ & $+?$ & + & + & + & $-?$ & $-?$ & $+?$ & $1 \mathrm{R} ?$ \\
\hline 13 & 10.5 & + & $+?$ & + & + & + & + & + & + & + & $+?$ & $1 \mathrm{~L}$ \\
\hline 15 & 9.5 & + & + & + & + & + & + & + & - & - & + & $1 \mathrm{R}$ \\
\hline $16^{*}$ & 9.0 & + & - & - & $-?$ & + & + & - & + & + & + & $5 ?$ \\
\hline $17^{*}$ & 8.8 & + & - & - & + & + & + & - & + & + & + & 5 \\
\hline 28 & 5.5 & + & - & + & + & + & + & + & + & + & + & $?$ \\
\hline 30 & 5.1 & + & $\mathrm{f}$ & $\mathrm{f}$ & $\mathrm{f}$ & + & + & + & + & + & + & $1 \mathrm{~L}$ \\
\hline 31 & 4.7 & + & - & + & + & - & - & + & - & + & + & $?$ \\
\hline $31 a$ & 4.65 & - & - & - & - & + & + & - & + & - & $\dot{-}$ & $?$ \\
\hline 34 & 4.35 & + & - & - & - & - & + & + & + & + & - & 3 \\
\hline 35 & 4.3 & + & + & + & + & + & + & + & - & - & + & $1 \mathrm{R}$ \\
\hline 36 & 4.1 & + & + & + & + & + & + & + & + & + & f & $1 \mathrm{~L}$ \\
\hline 38 & 3.9 & + & + & + & + & + & + & + & - & - & - & $1 \mathrm{R}$ \\
\hline 40 & 3.7 & + & + & $-?$ & + & + & + & $-?$ & - & - & - & $1 \mathrm{R}$ \\
\hline 41 & 3.6 & + & + & $+?$ & + & + & $-?$ & + & - & - & $+?$ & $1 \mathrm{R}$ \\
\hline 43 & 3.2 & + & - & $\mathrm{f}$ & + & + & - & - & + & + & + & 4,5 \\
\hline $44 *$ & 3.05 & + & - & - & - & - & + & + & + & + & - & 3 \\
\hline
\end{tabular}

$\mathrm{f}=$ faint $\quad *=$ MIC-limited

isomic strains including those which lack chromosome 3, 4 , or 5. Of the five MIC-limited clusters, three are found on chromosome 5 , one on chromosome 3 , and one could not be mapped. A summary of the chromosomal distribution of the $5 \mathrm{~S}$ gene clusters is shown in Table 5.

Further refinement of the relative locations of the $5 \mathrm{~S}$ rRNA gene clusters on the right arm of chromosome 1 was possible using strains that differed in their length of deletion for chromosome $1 R$. These data are shown in Fig. 4, but will not be taken up until the end of the next section.

Ageing of the MIC leads to loss of some of the $5 S \mathrm{rRNA}$ gene clusters

The MIC is known to be vegetatively unstable especially in certain strains (Nanney 1957; Allen et al. 1967). It is relatively stable in the $B$ strain; however, evidence that we will present suggests that ageing of the MIC does occur in this strain for certain clones under prolonged culture. Six clones of the $B$ strain which differed in culture age were included in this study: B-2079X2 and B-2079X6 were the youngest, since they were derived from a mating in 1979. Next in age were B-18684 and B-18687N derived from a mating in 1968 but frozen for a few years in Nanney's laboratory and thawed around 1973 or 1974 (Nanney, personnal communication). The oldest clones are B-18684b (maintained at Michigan) and B-18687B (maintained by Bruns) derived from the 1968 mating but grown vegetatively in continuous culture since that time.

Table 6 compares the $5 \mathrm{~S}$ gene clusters that are present in the MIC of these six B strain clones. The maximum number of clusters is observed in the B-2079 clones; moreover, most of the same clusters are found in the sister clones $\mathrm{X} 2$ and $\mathrm{X} 6$ [exception: $4.7,4.65 \mathrm{~kb}$ difference; an extra cluster in X6. These differences are real as assessed by mixing experiments]. Fewer than 32 clusters are seen in the B-1868 clones. B-18687B is missing six clusters. One of these six clusters (the $2.95 \mathrm{~kb}$ cluster) is also missing from the same clone (B-18687N) maintained by Nanney, with freezing. B-18684 from the same mating pair as B-18687 (and maintained by Nanney, with freezing) is lacking only the $4.7 \mathrm{~kb}$ cluster. B-18684b from a different mating pair, and maintained at Michigan in continuous culture, lacks two clusters: the $4.7 \mathrm{~kb}$ and $3.05 \mathrm{~kb}$ clusters. Compared to the $\mathrm{MIC}$, the MAC patterns of these six B strain clones are very similar. Thus, ageing of the MIC has occurred in some of these clones, but the MAC has apparently not been affected, since the MAC pattern has been conserved during vegetative growth. 


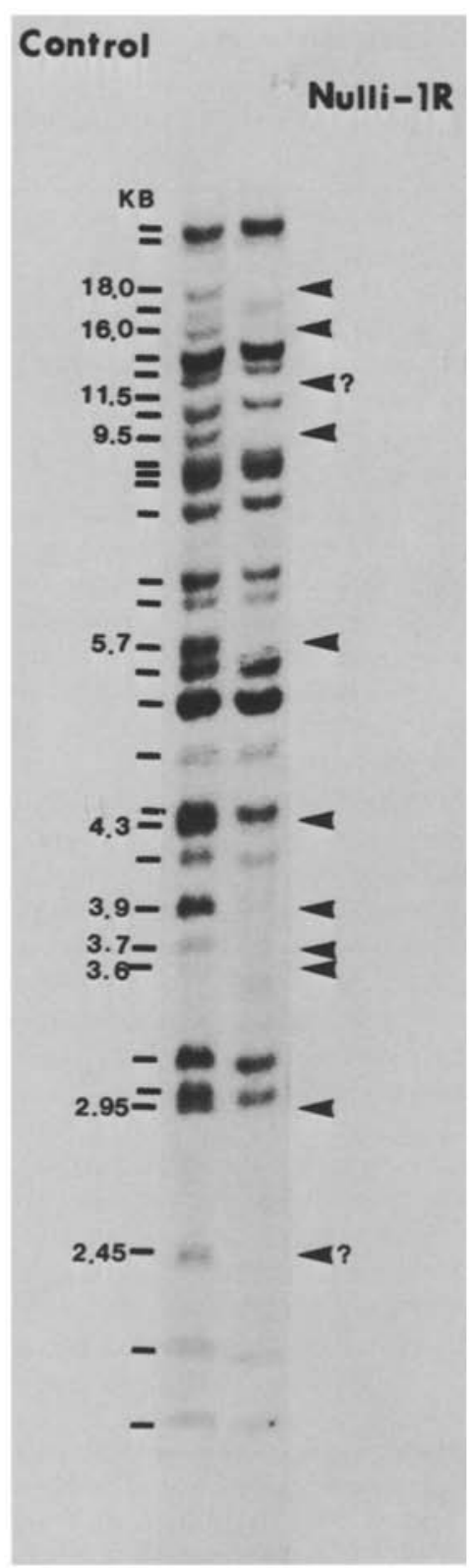

Fig. 3. Autoradiogram of Southern blot of DNA from the micronucleus (MIC) of B-2079X2 (control) and CU-373 (nulli-IR) probed with $\alpha^{32}$ P-labeled pDP5 (which contains one copy of the 5S DNA and spacer). The DNA's were digested with EcoRI $(5 \mu \mathrm{g} /$ lane), electrophoresed in an $0.6 \%$ agarose submarine gel, 12 inches long, for $60 \mathrm{~h}$ at $10 \mathrm{~mA}$, and blotted to nitrocellulose. Arrowheads point to fragments containing clusters missing in the MIC of the nulli-1 R strain. Their size in kilobases $(\mathrm{kb})$ is indicated to the left of the control MIC

That ageing of the MIC during vegetative culture is accompanied by chromosomal aberrations comes from examination of the chromosomal location of the $5 \mathrm{~S}$ gene clusters missing from the B-1868 clones. All six clusters missing from the MIC of B-18687B are located on the right arm of chromosome 1 . Thus, partial deletion of $1 \mathrm{R}$ has occurred for B-18687B. A much smaller deletion of $1 \mathrm{R}$ has occurred for B-18687N since only one of the six clusters has been lost. The relative length of these deletions can be determined by examining which $5 \mathrm{~S}$ gene clusters have been lost com-
Table 5. Chromosomal distribution of $5 \mathrm{~S}$ gene clusters

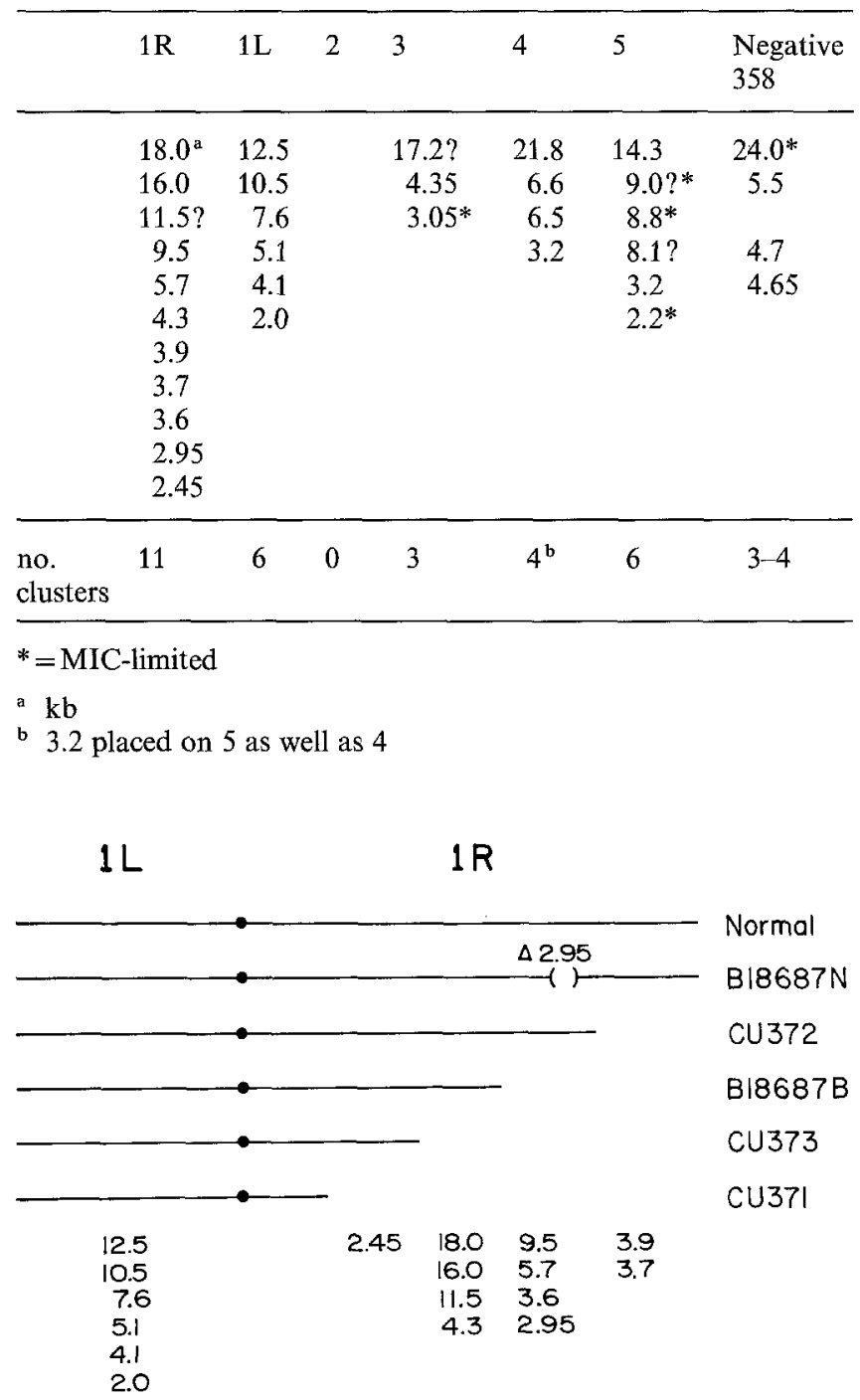

Fig. 4. Deletion map of chromosome 1. The $5 \mathrm{~S}$ gene clusters mapping to $1 \mathrm{~L}$ are present in all strains. The $5 \mathrm{~S}$ gene clusters mapping to $1 \mathrm{R}$ are positioned according to the length of the deletion present in the various strains. For example, only the 3.7 and $3.9 \mathrm{~kb}$ clusters are absent from CU372, while all eleven clusters are absent in CU371

pared to those missing in the nullisomic strains CU371, CU372, and CU373. The longest deletions occur in CU371 and CU373, with CU371 having a possible longer deletion than CU373. The length of the deletion in B-18687B appears to be less than that found in CU373 but greater than that found in CU372. A deletion map of chromosome 1 is the result (Fig. 4). Various 5S gene clusters can be grouped as to their location on the right arm of chromosome 1R. The deletions are shown as extending inward from the telomere of the right arm of chromosome 1, except for the deletion in B18687N. This deletion is shown as occurring internally since the $2.95 \mathrm{~kb}$ cluster is absent from B18687N but present in CU372.

A modest beginning of a deletion map for chromosome 3 is possible. B-18684b lacks the $3.05 \mathrm{~kb}$ MIC-limited cluster located on chromosome 3 but it has the 17.2 and $4.35 \mathrm{~kb}$ clusters, also found on this chromosome. Whether the right or left arm of chromosome 3 is the locus for one, or all, 
Table 6. 5S gene clusters in the MIC of six B strain clones

\begin{tabular}{|c|c|c|c|c|c|c|c|}
\hline \multirow{2}{*}{$\begin{array}{l}\text { Frag- } \\
\text { ment } \\
\text { no. }\end{array}$} & \multirow{2}{*}{$\begin{array}{l}\text { Size } \\
\mathrm{kb}\end{array}$} & \multicolumn{2}{|c|}{ B-2079 } & \multicolumn{4}{|c|}{ B-1868 } \\
\hline & & $\mathrm{X} 2$ & X6 & $4 b$ & 4 & $7 \mathrm{~N}$ & $7 \mathrm{~B}$ \\
\hline $3^{*}$ & 24.0 & + & + & + & + & + & + \\
\hline 4 & 21.8 & + & + & + & + & + & + \\
\hline 6 & 18.0 & + & + & + & + & + & f \\
\hline 7 & 17.2 & + & + & + & + & + & + \\
\hline 8 & 16.0 & + & + & + & + & + & $\mathrm{f}$ \\
\hline 10 & 14.3 & + & + & + & + & + & + \\
\hline 11 & 12.5 & + & + & + & + & + & + \\
\hline 12 & 11.5 & $f$ & $\mathrm{f}$ & + & $f$ & $\mathrm{f}$ & $?$ \\
\hline 13 & 10.5 & + & + & + & + & + & + \\
\hline 15 & 9.5 & + & + & + & + & + & - \\
\hline $16^{*}$ & 9.0 & + & + & + & + & + & + \\
\hline $17^{*}$ & 8.8 & + & + & + & + & + & + \\
\hline 18 & 8.1 & + & + & + & + & + & + \\
\hline 19 & 7.6 & + & + & + & + & + & + \\
\hline 23 & 6.6 & + & + & + & + & + & + \\
\hline \multirow[t]{2}{*}{24} & 6.5 & + & + & + & + & + & + \\
\hline & & & + & & & & \\
\hline 27 & 5.7 & + & + & + & + & + & - \\
\hline 28 & 5.5 & + & + & + & + & + & + \\
\hline 30 & 5.1 & + & + & + & + & + & + \\
\hline 31 & 4.7 & + & & - & - & + & + \\
\hline $31 \mathrm{a}$ & 4.65 & & + & & & & \\
\hline 34 & 4.35 & + & + & + & + & + & + \\
\hline 35 & 4.3 & + & + & + & + & + & $\mathrm{f}$ \\
\hline 36 & 4.1 & + & + & + & + & + & $\mathrm{f}$ \\
\hline 38 & 3.9 & $+^{\mathrm{a}}$ & $+^{a}$ & + & + & + & - \\
\hline 40 & 3.7 & + & + & + & + & + & - \\
\hline 41 & 3.6 & + & + & + & + & + & - \\
\hline 43 & 3.2 & + & + & + & + & + & + \\
\hline $44^{*}$ & 3.05 & + & + & - & + & + & + \\
\hline 45 & 2.95 & + & + & + & + & - & - \\
\hline 47 & 2.45 & + & + & + & + & + & $\mathrm{f}$ \\
\hline $48^{*}$ & 2.2 & + & + & + & + & + & + \\
\hline 49 & 2.0 & + & + & + & + & + & + \\
\hline \multicolumn{2}{|c|}{ Total no. clusters } & 32 & 33 & 30 & 31 & 31 & 26 \\
\hline \multicolumn{2}{|c|}{ Total kb } & 263 & 269 & 255 & 258 & 260 & 234 \\
\hline
\end{tabular}

$\mathrm{f}=$ faint $\quad *=$ MIC-limited

a Bands missing in the MAC. All other bands normally found in both MIC and MAC are present in the MAC even when absent from the MIC. MAC-limited bands (28, 19.6, 7.8, 7.1, $6.9,6.1,5.8 \mathrm{~kb})$ are found in all clones; the largest MAC-limited band $(30 \mathrm{~kb})$ is absent in the B-2079 clones but present in all of the B-1868 clones

of these clusters could be determined by using MIC from the nullisomic strain CU378 (nulli-3R, 4, 5). This has not, as yet, been done.

\section{Discussion}

The organization of the $5 \mathrm{~S}$ rRNA genes in the genome of Tetrahymena thermophila is similar to that of the wellstudied eukaryotes, Drosophila and Xenopus, in that the genes are arranged in tandem arrays of alternating transcribed and spacer sequences (Kimmel and Gorovsky 1978; Long and Dawid 1980). Moreover, the $5 \mathrm{~S}$ genes are not linked to the 18-28S rRNA genes as is also the case for other higher eukaryotes and for the acellular slime mold Physarum polycephalum (Long and Dawid 1980; Hall and Braun 1977), but is unlike the situation in the yeast Sacchar- omyces cerevisiae or the cellular slime mold Dictyostelium discoideum, where linkage occurs (Maizels 1976; Rubin and Sulston 1973). In Tetrahymena none of the 5S genes are found on chromosome 2, the site of the $r d n A$ locus, which contains the 17-26S rRNA genes. Instead, clusters of 5S genes, found on various sized $E c o$ RI fragments, are distributed to chromosomes 1, 3, 4, and 5 .

Previous estimates of the number of $5 \mathrm{~S}$ genes in $T$. thermophila have varied from 300-350 (Kimmel and Gorovsky 1976) to 780 (Tønnesen et al. 1976). Using densitometry to trace autoradiograms of Southern blots of EcoRI fragments probed with the $5 \mathrm{~S}$ gene, we attempted to quantitate the number of $5 \mathrm{~S}$ repeats for each cluster by integrating the tracings and measuring the area under the peaks. Since several problems are inherent in quantitating Southern blots, only trends in the data can be pointed out. First, we obtained minimal values for the total number of copies of the $5 \mathrm{~S}$ genes in fragments $2 \mathrm{~kb}$, or greater: $\sim 150$ for the MIC and $\sim 200$ for the MAC. These values could be doubled if fragments assumed to have only two copies of the $5 \mathrm{~S}$ genes have four copies.

Second, approximately $33 \%$ more copies of the $5 \mathrm{~S}$ genes were observed $\mathrm{n}$ in the MAC compared to the MIC. Earlier, Kimmel and Gorovsky (1976) reported a difference in copy number in MIC and MAC. They found that the MAC contained some $20 \%$ more copies compared to the MIC even after correcting for a MAC haploid genome size assumed to be $80 \%$ of that of the MIC. They could not attribute the small difference in copy number to any specific biological or technical cause. However, they could conclude that gene amplification from a single MIC copy, as it occurs for the 17-26 S rRNA genes, is not involved. Our results could be interpreted to suggest that modest amplification of the 5S rRNA genes may occur during the formation of the MAC. Out of the 27 clusters on fragments of the same size in MIC and MAC, 16 of the clusters contain more gene copies in the MAC. One attractive way this increase in copy number might occur would be if, after chromosome fragmentation during MAC formation, the 250, or so, chromosomal fragments did not undergo identical rounds of replication, but that some might replicate more, and others less, than average. Chromosome fragments bearing $5 \mathrm{~S}$ gene copies might replicate more than average.

Previous work suggested that the 300-350 5S gene copies in Tetrahymena were organized as 15-20 tandem arrays, each cluster containing 15-20 repeats (Kimmel and Gorovsky 1978). This view of $5 \mathrm{~S}$ gene organization now needs to be modified to take into consideration our finding that the number of $E c o$ RI fragments containing $5 \mathrm{~S}$ gene clusters is probably double the earlier figure. Moreover, the minimum average size cluster contains 5-6 gene copies, some clusters having as few as 2-3 gene copies and others as many as $10-11$ gene copies.

The $5 \mathrm{~S}$ gene organization appears to be conserved in the MIC genome of different inbred strains of $T$. thermophila. The majority of cluster-bearing fragments are similar in size, with only a few size changes observed in certain strains. Whether there are changes in gene copy number in the tandem arrays on fragments of the same size in different strains has not, as yet, been determined. The total number of fragments with clusters is similar, and similar values are seen for the newly formed MAC of these strains. The majority of fragments that persist in the MAC are found in all strains. There is also concordance in which 
MIC-limited and which MAC-limited clusters are present among strains of common ancestry. These observations suggest that not only is there conservatism in the $5 \mathrm{~S}$ gene organization of the MIC but that the reorganization of these genes in the genome that occurs with the development of the MAC is conserved in different strains. However, as we will show, there are differences in the constellation of fragments present in the MAC of cell clones of certain strains (Allen et al., manuscript submitted). Moreover, during vegetative growth as MAC DNA is replicated, about half the fragments bearing $5 \mathrm{~S}$ gene clusters disappear, and new clusters on EcoRI fragments that differ in size from those present in the MIC, or newly formed MAC, appear.

The distributions of the $5 \mathrm{~S}$ gene clusters on the MIC chromosomes does not appear to be random. More than half of the clusters are located on chromosome 1. None occur on chromosome 2 where the $r d n A$ locus is situated. The remaining clusters are distributed to chromosomes 3 , 4 , and 5. Three of the MIC-limited clusters occur on chromosome 5 , one on chromosome 3 , and one has not yet been mapped. The use of deletion strains permits the construction of a crude deletion map for the 17 clusters found on chromosome 1. However, nothing is known as to the physical length of these deletions. They could all be relatively long, as drawn in Fig. 4. Or, they could all be much shorter, and the clusters, as a group, might map closer to the telomere.

The copy number of the $5 \mathrm{~S}$ genes in Tetrahymena is similar to that of Drosophila or to the somatic family of 5S genes in Xenopus (Long and Dawid 1980). However, the chromosomal distribution of the $5 \mathrm{~S}$ gene clusters is unlike either that found for Drosophila or for Xenopus. A single cluster of about $1605 \mathrm{~S}$ genes occurs on chromosome 2 at location 56F in Drosophila melanogaster (Procunier and Tartof 1975; Wimber and Steffensen 1970), whereas the many 5S genes of Xenopus laevis are dispersed in many clusters at the telomeres on most, if not all, chromosomes (Pardue et al. 1973). We do not know the precise chromosomal locations for the $5 \mathrm{~S}$ genes in Tetrahymena thermophila; i.e., whether they are found at the telomeres, or at other particular locations. In other organisms the chromosomal location of the $5 \mathrm{~S}$ gene clusters can be near telomeres (Pardue et al. 1973), centromeres (Pukkila 1975), or in between (Wimber and Steffensen 1970).

Loss of $5 \mathrm{~S}$ gene clusters was observed in the MIC of ageing cultures of B strain clones. Since the affected clusters were located on specific chromosome parts, the loss of these clusters could be attributed to deletion of specific chromosome segments. That the MIC ages is not a new observation (Nanney 1957). It has been known for some time that the MIC is unstable and that this instability leads to loss of fertility in crosses and irregularities in genetic transmission (Nanney 1963). Genomic exclusion occurs in crosses of certain star strains which are aneuploid (Allen 1967b). In these strains some lineages produce amicronucleate cells, which die in the laboratory (Allen et al. 1967). Since normal progeny are not produced, or are produced in very low numbers, when lines with defective MIC are used in crosses, considerable effort is needed to prevent deterioration of the MIC by stringent selection of lines that have a MIC and give rise to normal progeny. This was accomplished by yearly rounds of inbreeding of all strains up until 1968, or by freezing the strains, thereafter.

Loss of the MIC can occur at any fission. In certain genotypes the probability is high that loss will occur within 100-200 fissions, or so; however, in "normal" genotypes the probability of loss is so low that this event is not observed before 1000 fissions (Nanney 1959). The B strain has one of those genotypes in which the MIC is most stable. What is new in this paper is documentation of chromosome deletions in cultures of $\mathrm{B}$ strain clones now more than 1500 fissions old. This is best seen with clone B-18687B which is considered by most researchers to represent a normal $T$. thermophila genome. The MIC has lost at least six fragments containing $5 \mathrm{~S}$ rRNA gene clusters. Through our mapping of the 5S gene clusters, we could show that clone B-18687B has lost part of the right arm of chromosome 1. The lesson to be learned is due caution in using cultures that have not been frozen or recently inbred.

\section{Conclusions}

The organization of the 5S rRNA genes in the MIC of Tetrahymena is similar to that of other eukaryotes, such as Drosophila or Xenopus, in that the genes are arranged in tandem arrays of alternating transcribed and spacer sequences. These genes are not linked to the 17-26S rRNA genes found at the $r d n A$ locus on chromosome 2. Clusters containing two to ten copies (or four to 20 copies) of the $5 \mathrm{~S}$ genes are found on $32 \mathrm{Eco} \mathrm{RI}$ fragments, $2 \mathrm{~kb}$, or larger, which are dispersed on chromosomes 1, 3, 4 and 5. Seventeen of the clusters are located on chromosome 1, and a crude deletion map has been constructed that groups the clusters to various segments of chromosome 1 . Some of these deletions were found in the MIC of ageing cultures of $\mathrm{B}$ strain clones. The organization of the $5 \mathrm{~S}$ genes is conserved in different inbred strains, with some changes observed in the MIC genomes among strains of common ancestry. During development of the MAC only minimal reorganization of the $5 \mathrm{~S}$ genes occurs, the pattern of reorganization being conserved in different strains. However, the number of copies of the $5 \mathrm{~S}$ genes increases by $33 \%$. Differential replication during MAC formation of chromosomal fragments bearing $5 \mathrm{~S}$ gene clusters might account for this increase.

Acknowledgements. Supported by research grants, GM-27703 from the National Institute of General Medical Sciences, U.S. Public Health Service, and PCM-8300502 from the National Sciences Foundation. We thank Peter $\mathbf{J}$. Bruns for his never failing enthusiasm for our mapping results, David Pederson for sending us pDP5, Martin A. Gorovsky for his suggestion of the method for determining $5 \mathrm{~S}$ gene copy number, Theodore $\mathrm{C}$. White for help with the densitometry and Almuth $\mathrm{H}$. Tschunko for her drawing of Figs. 1 and 4.

\section{References}

Allen SL (1967a) A rapid means for inducing homozygous diploid lines in Tetrahymena pyriformis syngen 1. Science 155:575-577

Allen SL (1967b) Cytogenetics of genomic exclusion in Tetrahymena. Genetics 55:797-822

Allen SL, Lee PHT (1971) The preparation of congenic strains of Tetrahymena. J Protozool 18:214-218

Allen SL, File SK, Koch SL (1967) Genomic exclusion in Tetrahymena. Genetics 55:823-837

Ailen SL, Ervin PR, White TC, McLaren NC (1984) Rearrangement of the 5S ribosomal RNA gene clusters during the development and replication of the macronucleus in Tetrahymena thermophila. Submitted to Dev Genet 
Allen SL, White TC, Langmore JP, Swancutt MA (1983) Highly purified micro- and macronuclei from Tetrahymena thermophila isolated by percoll gradients. J Protozool $30: 21-30$

Brunk CF, Tsao SGS, Diamond CH, Ohashi PS, Tsao NNG, Pearlman, RE (1982) Reorganization of unique and repetitive sequences during nuclear development in Tetrahymena thermophila. Can J Biochem 60:847-853

Bruns PJ (1982) Tetrahymena thermophila. Genetic Maps $2: 178-181$

Bruns PJ, Brussard TB, Merriam EV (1983) Nullisomic Tetrahymena II. A set of nullisomics define the germinal chromosomes. Genetics 104:257-270

Callahan RC, Shalke G, Gorovsky MA (1984) Developmental rearrangements associated with a single type of expressed $\alpha$-tubulin gene in Tetrahymena. Cell 36:441-445

Denhardt D (1966) A membrane-filter technique for the detection of complementary DNA. Biochem Biophys Res Commun 23:641-652

Gorovsky MA (1980) Genome organization and reorganization in Tetrahymena. Annu Rev Genet 14:203-239

Gunsalus RP, Zurawski G, Yanofsky C (1979) Structural and functional analysis of cloned deoxyribonucleic acid containing the trpR-thr regions of the Escherichia coli chromosome. J Bacteriol 140:106-113

Hall L, Braun R (1977) The organization of genes for transfer RNA and ribosomal RNA in amoebae and plasmodia of $P h y-$ sarum polycephalum. Eur J Biochem 76:165-174

Iwamura Y, Sakai M, Muramatsu M (1982) Rearrangement of repeated DNA sequences during development of macronucleus in Tetrahymena thermophila. Nucl Acids Res 10:4279-4291

Kimmel AR, Gorovsky MA (1976) Numbers of 5S and tRNA genes in macro- and micronuclei of Tetrahymena pyriformis. Chromosoma 54:327-337

Kimmel AR, Gorovsky MA (1978) Organization of the 5S RNA genes in macro- and micronuclei of Tetrahymena pyriformis. Chromosoma 67:1-20

Long EO, Dawid IB (1980) Repeated genes in eukaryotes. Annu Rev Biochem 49:727-764

Maizels N (1976) Dictyostelium 17S, 25S, and 5S rDNAs lie within a 38,000 base pair repeat unit. Cell 9:431-438

Maniatis T, Jeffrey A, Kleid AG (1975) Nucleotide sequence of the rightward operator of phage $\lambda$. Proc Natl Acad Sci USA 72:1184-1188

Nanney DL (1957) Inbreeding degeneration in Tetrahymena. Genetics $42: 137-147$

Nanney DL (1959) Vegetative mutants and clonal senility in Tetrahymena. J Protozool 6:171-177

Nanney DL (1963) Irregular genetic transmission in Tetrahymena crosses. Genetics 48:737-744

Pace NR (1973) The structure and synthesis of the ribosomal ribonucleic acid of prokaryotes. Bacteriol Rev 37:562-603
Pardue ML, Brown DD, Birnstiel ML (1973) Location of the genes for $5 \mathrm{~S}$ ribosomal RNA in Xenopus laevis. Chromosoma 42:191-203

Pearlman RE, Andersson P, Engberg J, Nilsson JR (1979) Synthesis of ribosomal DNA in conjugating Tetrahymena. Exptl Cell Res 123:147-155

Procunier JD, Tartof KD (1975) Genetic analysis of 5S RNA genes in Drosophila melanogaster. Genetics $31: 515-523$

Pukkila PJ (1975) Identification of the lampbrush chromosome loops which transcribe 5S ribosomal RNA in Notophthalmus (Triturus) viridescens. Chromosoma 53:71-89

Rigby PWJ, Dieckmann M, Rhodes C, Berg P (1977) Labeling deoxyribonucleic acid to high specific activity in vitro by nick translation with DNA polymerase I. J Mol Biol 113:237-251

Rubin GM, Sulston JE (1973) Physical linkage map of the 5S cistrons to the $18 \mathrm{~S}$ and $28 \mathrm{~S}$ ribosomal RNA cistrons in Saccharomyces cerevisiae. J Mol Biol 79:521-530

Southern E (1975) Detection of specific sequences among DNA fragments separated by gel electrophoresis. J Mol Biol 98:503-517

Tønnesen T, Engberg J, Leick V (1976) Studies on the amount and location of the tRNA and 5-S rRNA genes in Tetrahymena pyriformis GL. Eur J Biochem 63:399-407

Wimber DE, Steffensen DM (1970) Localization of 5S RNA genes in Drosophila chromosomes by RNA-DNA hybridization. Science 170:639-641

Yao MC (1982) Eliminatin of specific DNA sequences from the somatic nucleus of the ciliate Tetrahymena. J Cell Biol 92:783-789

Yao MC, Gall JG (1977) A single integrated gene for ribosomal RNA in a eukaryote, Tetrahymena pyriformis. Cell 12:121-132

Yao MC, Yao CH (1981) Repeated hexanucleotide C-C $-\mathrm{C}-$ $\mathrm{C}-\mathrm{A}-\mathrm{A}$ is present near free ends of macronuclear DNA of Tetrahymena. Proc Natl Acad Sci USA 78:7436-7439

Yao MC, Kimmel AR, Gorovsky MA (1974) A small number of cistrons for ribosomal RNA in the germinal nucleus of a eukaryote, Tetrahymena pyriformis. Proc Natl Acad Sci USA $71: 3082-3086$

Yao MC, Blackburn E, Gall JG (1979) Amplification of the rRNA genes in Tetrahymena. Cold Spring Harbor Symp Quant Biol 43:1293-1296

Yao MC, Choi J, Yokoyama S, Austerberry CF, Yao CH (1984) DNA elimination in Tetrahymena: a developmental process involving extensive breakage and rejoining of DNA at defined sites. Cell 36:433-440

Communicated by G.R. Fink

Received March 23 / June 20, 1984 